\title{
APPLICATION OF D-OPTIMAL DESIGN FOR THE OPTIMIZATION \\ OF ISOLATED PIPERINE FROM PIPER NIGRUM L-LOADED SELF-NANOEMULSIFYING DRUG DELIVERY SYSTEMS (SNEDDS)
}

\author{
NINDYA KUSUMORINI ${ }^{1}$, AKHMAD KHARIS NUGROHO ${ }^{2 *}$, SUWIJIYO PRAMONO ${ }^{3}$, \\ and RONNY MARTIEN ${ }^{2}$
}

\author{
${ }^{1}$ Doctoral Program in Pharmaceutical Science, Faculty of Pharmacy, \\ ${ }^{2}$ Department of Pharmaceutics, Faculty of Pharmacy, \\ ${ }^{3}$ Department of Pharmaceutical Biology, Faculty of Pharmacy, Universitas Gadjah Mada, \\ Yogyakarta 55281 Indonesia
}

\begin{abstract}
The current study was designed to optimize isolated piperine in the self-nano emulsifying drug delivery system (SNEDDS) using a D-Optimal design. SNEDDS optimization was used to obtain the optimum formula according to the common characteristics. Cremophor RH40 (surfactant), PEG400 (co-surfactant), and Miglyol $812 \mathrm{~N}$ (oil) were used as independent factors. The SNEDDS characteristics, which included percent transmittance, emulsification time, particle size, and zeta potential, were used as responses to determine the optimum formula. The obtained SNEDDS optimum formula was evaluated according to percent transmittance, emulsification time, compound content, particle size, and zeta potential with the results obtained $96.34 \pm 0.33 \%, 14.91 \pm 0.10$ second, $19.88 \pm 0.10 \mathrm{mg} / \mathrm{g}, 33.35 \pm 1.97$, $\mathrm{nm}$ and $-22.87 \pm 3.31 \mathrm{mV}$, respectively. In conclusion, the D-Optimal design demonstrates its effectiveness in optimizing the SNEDSS isolated piperine formulation and identifying the effects of the formulation variables.
\end{abstract}

Keywords: piperine, D-optimal design, SNEDDS, optimization, bioavailability

The administration of drugs via the oral route is the most uncomplicated drug administration to accept by patients. Nearly two-thirds of the world's drug is administered by mouth (1). However, many active compounds have solubility problems and low release profiles in aqueous media. It has been a challenge for scientists to increase the solubility and permeability of these drugs to increase bioavailability. Various strategies have been used to overcome low solubility and permeability, including particle size reduction (2), solid dispersion and salt formation (3), surfactant, nanoparticles, nano-emulsions (4), complexation with cyclodextrin (5), and lipid-based formulation of self-emulsifying drug delivery system (SEDDS) (6).

White pepper, the king of spices, has been commonly used as kitchen spice and traditional medicine (7). Piperine, the main alkaloid compound in the white pepper, is thought to play the most crucial role in this treatment. Recent studies on piperine's pharmacological effects have reported several effects, including antidepressant (8), anti-inflammatory, analgesic, antipyretic (9), antioxidant, anti-metastatic, hepatoprotective (10), antitumor, anti-thyroid, immunomodulator, inhibition of P-glycoprotein expressed by cancer cells (11-13), and increasing the bioavailability of other drugs through cell membranes by increasing vasodilation of the GIT membrane (14). Despite its pharmacological benefits, piperine has low solubility and dissolution, which become its ratelimiting steps in the absorption process. Piperine has a water solubility of $22.34 \mathrm{mg} / \mathrm{L}$ at $25^{\circ} \mathrm{C}$. It is lipophilic with a $\log \mathrm{P}$ value of 2.25 (15) and has good permeability based on an analysis of piperine structure according to Lipinski and Veber's rules (16). The SNEDDS formulation was selected to improve the physicochemical characteristics of the isolated piperine.

SNEDDS is a lipid-based formulation consisting of a mixture of isotropic anhydrous liquid or solid surfactant, co-surfactant, and synthetic or natural oils, which can form oil in water (o/w) emulsions spontaneously through mild agitation in gastrointestinal fluids (17). The spontaneous formation

* Corresponding author: e-mail: a.k.nugroho@ugm.ac.id 
of micro-emulsions can deliver drugs in a dissolved form. The small droplet size allowed the dissolved drug to quickly and easily be absorbed because it has a large surface area and can increase permeation across the intestinal membranes (18). SNEDDS formulation has several advantages, including improving drug solubility, lowering drug dosages, bypassing lymphatic transport, increasing long-term storage, having a fast onset, and not being affected by food $(6,19,20)$. The following are some SNEDDS products successfully marketed commercially. Including Sandimmune ${ }^{\circledR}$ and Sandimmun Neoral ${ }^{\circledR}$ (Cyclosporine A, Novartis), Norvir ${ }^{\circledR}$ (Ritonavir), and fortovase ${ }^{\circledR}$ (Saquinavir). A significant increase in the bioavailability of these drugs has been shown in each case $(21,22)$.

An experimental design approach was selected to develop and optimize formulations to streamline the required time and costs in trial experiments and errors. In the experimental design, one can obtain a systematic formulation design based on statistical criteria to receive an optimum final product by reducing the number of levels tested $(23,24)$. D-optimal design is one of the experimental designs that has been widely used for optimization in the pharmaceutical industry. Using the design, the total number of independent variables produced in each run has always been constant, resulting in a 100 percent mixture (25). The D-optimal design has been used to obtain superior physicochemical characteristics such as high solubility of drug compounds and small particle sizes. The design has also been used systematically to investigate the effect of independent variables (amount of surfactant, co-surfactant, and oil) and dependent variables (percent transmittance response, emulsification time, particle size, and zeta potential).

In the SNEDDS formulation, the percentage of oil, surfactant, and cosurfactant in the formulation affects the characteristics of SNEDDS itself. Therefore, it is important to determine the optimal quantity of oil, surfactant, and cosurfactant to obtain the desired characteristics. This research design and optimize the composition of oil, surfactant, and cosurfactant containing piperine compounds. In this study, Cremophor RH40 was chosen as the surfactant, PEG400 as the cosurfactant, and Miglyol $812 \mathrm{~N}$ as the oil. These three ingredients have been proven safe for oral formulations. Even the surfactant Cremophor RH40 (polyoxy 40 hydrogenated castor oil) has been successfully used for the SNEDDS formulation products on the market. Namely, the Neural ${ }^{\circledR}$ (Novartis) product contains cyclosporine $\mathrm{A}$ and is given 2-4 times a day, so that the patient consumes approximately 2-3 g Cremophor daily, it is still safe to use where this value is far from the LD50 value of nonionic surfactants, which is $50 \mathrm{~g} / \mathrm{kg}(26,27,28)$. The determination of the range of surfactants, cosurfactants, and MCT (mediumchain triglyceride) oil was on the safe limit for use in oral preparations and their ability to form stable SNEDDS, which ranged from $30-60 \%(\mathrm{~m} / \mathrm{m})$ for hydrophilic surfactants HLB $>12$ (HLB Cremophor RH40) (15), cosurfactants 20-50\%, and glycerides (mono-, di-,tri-glycerides) $<20 \%(29,30)$.

\section{EXPERIMENTAL}

\section{Materials}

Isolated piperine $(94.57 \%$ purity) was obtained from the isolation of white pepper (Piper nigrum L) (Sorowako, South Sulawesi, Indonesia), piperine standards with 98\% purity (Merck, China), Cremophor RH40 (Clariant, Indonesia), Miglyol 812 N (IOI Oleochemical, Germany), PEG 400 (Brataco, Indonesia), water for injection (WFI) (IKA Pharmindo, Indonesia), and methanol HPLC grade (Merck, Germany).

\section{Instrumentation}

The instruments used in the research include stirrer (Stuart Hotplate Stirrer CB162, UK), analytical balance (Ohaus PA 323, China), semi-micro analytical balance (Shimadzu AP135W, Japan), vortex (D-Lab MX-S, USA), centrifuge (Hettich, EBA 8, Germany), HPLC Hitachi L-2420 UV-Vis detector with Luna ${ }^{\circledR} 5 \mu \mathrm{m} \mathrm{C18} 100 \AA$ LC Column $250 \mathrm{x}$ $4.6 \mathrm{~mm}$ Phenomenex (Hitachi, Japan), UV-Vis spectrophotometer (Genesys 10S, USA), and Malvern Zetasizer (Malvern Instruments, UK).

\section{Preparation of isolated-piperine-loaded SNEDDS}

SNEDDS containing isolated piperine was made by mixing isolated piperine with Cremophor RH40, PEG400, and Miglyol $812 \mathrm{~N}$ using a stirrer (Stuart Hotplate Stirrer CB162) for 30 minutes. The amount of the three excipients was determined based on the D-optimal designs statistical results using Design-Expert software. The physical properties of each run experiment were characterized in order to determine the optimum formula.

\section{SNEDDS Optimization}

Three independent factors were used to optimize the isolated piperine-loaded SNEDDS composition using the D-Optimal design results of Design-Expert software (DX ver.10, State Ease Inc, 
Minnesota). The study involved five replications of the D-optimal design, and 16 trial runs were conducted to determine the optimum formula of the effects of the independent variables. The selected independent variables were Cremophor RH40 (57.50-70\%) as a surfactant, PEG 400 (15-30\%) as a co-surfactant, and Miglyol $812 \mathrm{~N}(8.50-25 \%)$ as the oil phase. The percent transmittance response (Y1), emulsification time (Y2), particle size (Y3), and zeta potential (Y4) were selected to assess the isolated piperine-loaded SNEDDS.

\section{Determination of percent transmittance}

The transmittance percentage of SNEDDS formulation was measured by dissolving $100 \mu \mathrm{L}$ of SNEDDS isolated piperine in $10 \mathrm{~mL}$ of distilled water homogenized with a stirrer. The isotropic system's clarity was read using a UV spectrophotometer (Genesys 10S) at a wavelength of $650 \mathrm{~nm}$ (31).

\section{Determination of emulsification time}

The emulsification time of SNEDDS was measured by dropping $1 \mathrm{~mL}$ of SNEDDS isolated piperine into $500 \mathrm{~mL}$ of distilled water at $37^{\circ} \mathrm{C}$ conditioned on a magnetic stirrer at a speed of $120 \mathrm{rpm}$. The emulsification process was carried out in the time required to form a homogeneous SNEDDS droplet mixture in the medium (31).

\section{Determination of droplet size, poly-dispersity index (PDI), and zeta potential}

The particle size, poly-dispersity index, and zeta potential were analyzed by diluting $1 \mathrm{~mL}$ of SNEDDS isolated piperine in add $100 \mathrm{~mL}$ of distilled water and homogenized using a magnetic stirrer, and then analyzing the mixture using Malvern Zetasizer (Malvern Instruments, UK) where light scattering was monitored at $25^{\circ} \mathrm{C}$ and an angle of $172^{\circ} \mathrm{C}(32)$.

\section{Determination of drug content}

The content of isolated piperine was determined using high-performance liquid chromatography. Column C18 Phenomenex ${ }^{\circledR}$ size 250 x 4 mm, $5 \mu \mathrm{m}$ was used as the stationary phase, while methanol : water $(75: 25 \% \mathrm{v} / \mathrm{v})$, with a UV $340 \mathrm{~nm}$ detector with a mobile phase flow rate of $1 \mathrm{~mL} /$ minute was used as the mobile phase. The HPLC methods analyzed in the validation included specification, linearity, precision, accuracy, the limit of detection (LOD), and the limit of quantification (LOQ).

The isolated piperine was weighed and dissolved in methanol to produce a $1 \mathrm{mg} / \mathrm{mL}$ stock solution. Linearity was tested in standard solution in a range of $0.20-1.00 \mu \mathrm{g} / \mathrm{mL}$ to determine the calibration curve with each concentration level was prepared in triplicate. The data of solution concentration and area were plotted graphically to obtain the linear regression equation $\mathrm{y}=\mathrm{bx}+\mathrm{a}$. Precision was tested by preparing three concentrations of standard solutions analyzed on the same day (intraday) and repeated on a different day (interday) to determine the relative standard deviation (RSD). Accuracy was tested by preparing three concentrations of standard solution spiked with placebo to determine the percent recovery. LOD and LOQ values were determined from the response and slope of the calibration curve of the standard solution $(10-100 \mu \mathrm{g} / \mathrm{L})$.

\section{Statistical analysis}

The independent variable responses, which include $\%$ transmittance, emulsification time, particle size, and zeta potential, were analyzed using Design-Expert software. An analysis of variance was performed to determine the significance of the statistically-based model. The optimum formula obtained was validated, and the response results were analyzed using a one-sample t-test with SPSS version 19 software.

\section{RESULTS AND DISCUSSION}

Piperine isolate, nonionic surfactant Cremophor RH40, co-surfactant PEG400, and Miglyol $812 \mathrm{~N}$ oil were selected as constituent components of SNEDDS. The components were optimized using a D-Optimal design to obtain a concentration ratio that could produce the optimum formula. The D-optimal design was selected to reduce the number of formulas needed to determine the optimum formula using a statistical approach. The determination of the optimum formula was based on the response generated from each run of the formula. The responses investigated included \% transmittance, emulsification time, particle size, and zeta potential. The optimum formula was determined based on the $p$-value of analysis of variance (ANOVA), lack of fit, $\mathrm{R}^{2}$, and adjusted- $\mathrm{R}^{2}$ to determine the optimal model according to the experimental data $(24,33)$. Following are the results of the D-optimal statistical analysis for each response:

\section{Percent transmittance}

The transmittance percentage was aimed to determine the isotropic property of SNEDDS, where a mixture of oil, water, and surfactant was required to produce a stable thermodynamic solution (24). A close to $100 \%$ percent transmittance value indicates the nanometer range's globule size (34). The 
Table 1. D-Optimal experimental design with measured responses.

\begin{tabular}{|c|c|c|c|c|c|c|c|}
\hline Run & $\begin{array}{c}\text { Cremophor RH40 } \\
(\%)\end{array}$ & $\begin{array}{c}\text { PEG400 } \\
(\%)\end{array}$ & $\begin{array}{c}\text { Miglyol 812 N } \\
(\%)\end{array}$ & $\begin{array}{c}\text { Percent } \\
\text { transmittance (\%) }\end{array}$ & $\begin{array}{c}\text { Emulsification } \\
\text { time (second) }\end{array}$ & $\begin{array}{c}\text { Droplet size } \\
(\mathrm{nm})\end{array}$ & $\begin{array}{c}\text { Zeta potential } \\
(\mathrm{mV})\end{array}$ \\
\hline 1 & 65.16 & 15 & 19.84 & 94.40 & 267 & 25.20 & -37.60 \\
\hline 2 & 57.66 & 20.73 & 21.61 & 90 & 102 & 27.70 & -36.60 \\
\hline 3 & 70 & 15 & 15 & 94.40 & 286.20 & 23.90 & -27.40 \\
\hline 4 & 61.50 & 30 & 8.50 & 94.90 & 40.20 & 25.90 & -21.80 \\
\hline 5 & 61.50 & 30 & 8.50 & 97 & 29.40 & 39.40 & -19.60 \\
\hline 6 & 64.54 & 24.82 & 10.64 & 96.10 & 66 & 39 & -34.80 \\
\hline 7 & 63.89 & 20.68 & 15.44 & 93.90 & 87 & 27.50 & -39.50 \\
\hline 8 & 70 & 21.50 & 8.50 & 96.50 & 82.80 & 34.40 & -40.10 \\
\hline 9 & 60 & 15 & 25 & 92.20 & 118.20 & 28.90 & -40.10 \\
\hline 10 & 57.50 & 29.74 & 12.76 & 95.90 & 49.80 & 30.90 & -39.10 \\
\hline 11 & 60 & 15 & 25 & 92.70 & 150 & 29.40 & -36.60 \\
\hline 12 & 70 & 21.50 & 8.50 & 97.50 & 52.20 & 54.84 & -37.70 \\
\hline 13 & 68.05 & 19.29 & 12.66 & 96.60 & 55.20 & 24.50 & -40.60 \\
\hline 14 & 57.50 & 29.74 & 12.76 & 96.30 & 37.80 & 33.30 & -40.90 \\
\hline 15 & 57.50 & 25.65 & 16.85 & 96.40 & 49.20 & 48.55 & -35 \\
\hline 16 & 70 & 15 & 15 & 95.80 & 168 & 27.50 & -38.80 \\
\hline
\end{tabular}

evaluation results of the percent transmittance of the 16 runs of SNEDDS formula for isolated piperine were in the range of $90-97 \%$ (Table 1). Based on the statistical evaluation of the D-optimal design, a regression equation for percent transmittance was: $\mathrm{Y} 1=+1.00 \mathrm{~A}+0.97 \mathrm{~B}+0.69 \mathrm{C}$, where $\mathrm{A}$ is Cremophor RH40, B is PEG400, C is Miglyol $812 \mathrm{~N}$. The equation showed that the surfactant Cremophor RH40 is significantly effective in increasing the percent transmittance.

\section{Emulsification time}

A good SNEDDS formulation must disperse rapidly and perfectly when diluted under mild agitation of gastrointestinal fluid due to peristaltic activity. The emulsification rate depends on the rate of spontaneous emulsification of oil in water $(\mathrm{o} / \mathrm{w})$ without the aid of thermal or mechanical energy (34). The ease of emulsification was associated with the ease of water penetration into the gel or colloid phase in the form of droplets on the surface (35). The emulsification time of the 16 runs of formulas was 29.40-286.20 seconds (Table 1). According to the statistical evaluation of the $\mathrm{D}$-optimal design, the regression equation for the emulsification time was $\mathrm{Y} 2=-52.83 \mathrm{~A}-306.48 \mathrm{~B}$ $-616.15 \mathrm{C}+6.43 \mathrm{AB}+11.74 \mathrm{AC}+33.44 \mathrm{BC}-$ $0.56 \mathrm{ABC}$. This equation shows that the interaction between co-surfactant PEG400 and Miglyol 812 N has the most significant effect on the increase in emulsification time.

\section{Particle size}

The emulsion droplet size was the most important factor in the SNEDDS formulation because it affects the drug release and absorption rate (34). The mean droplet size of the SNEDDS formulation was in the range of less than $200 \mathrm{~nm}$ (31). The small droplet size was ideal for producing a faster emulsification time, increasing lymphatic drug absorption, and increase drug therapy efficacy (36). The droplet size evaluation results of the 16 run formulas were in the range of 23.90-54.84 nm (Table 1). According to the statistical evaluation of the D-optimal design, the regression equation for the size of the droplets was: $\mathrm{Y} 3=+28.94 \mathrm{~A}-373.05 \mathrm{~B}-239.94 \mathrm{C}+6.37 \mathrm{AB}$ $+4.23 \mathrm{AC}+6.53 \mathrm{BC}-0.03 \mathrm{ABC}-0.05 \mathrm{AB}(\mathrm{A}-\mathrm{B})$ $-0.04 \mathrm{AC}(\mathrm{A}-\mathrm{C})+0.03 \mathrm{BC}(\mathrm{B}-\mathrm{C})$. The equation shows that the Cremophor RH40 surfactant is the most effective in increasing the droplet size, while PEG400 and Miglyol $812 \mathrm{~N}$ are the most effective in reducing it.

\section{Zeta potential}

The zeta potential value influences the electrostatic repulsion force, which contributes to the stability of the colloid disperse. An increase in the electrostatic repulsion between globules can prevent 


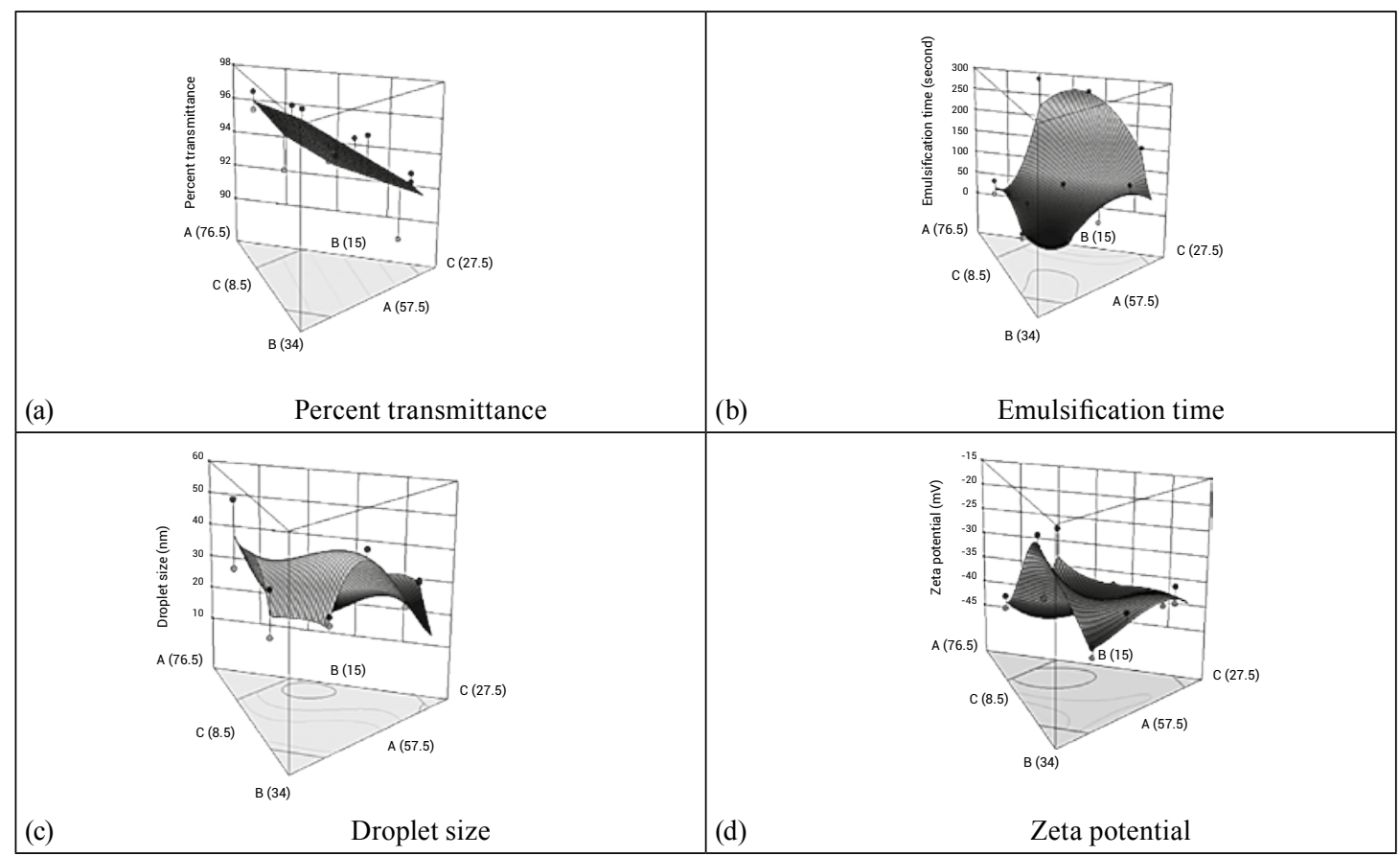

Figure 1. 3D-response surface plot showing the effect of independent variables on the responses (a) percent transmittance, (b) emulsification time, (c) droplet size, (d) zeta potential.

coalescence/fusion between droplets, while a decrease in electrostatic repulsion can cause a phase separation (31). The zeta potential value limit for SNEDDS ranges about $\pm 30 \mathrm{mV}$ (37). The zeta potential evaluation results of 16 run formulas ranged from $(-19.6)-(-40.9)(\mathrm{mV})$ (Table 1). Based on the statistical evaluation of the D-optimal design, the regression equation of zeta potential was: $\mathrm{Y} 4=+14.92 \mathrm{~A}-$ 186.83 $\mathrm{B}-71.03 \mathrm{C}+3.32 \mathrm{AB}+0.97 \mathrm{AC}+2.33 \mathrm{BC}$ $+7.10 \times 10^{-4} \mathrm{ABC}-0.03 \mathrm{AB}(\mathrm{A}-\mathrm{B})-0.01 \mathrm{AC}(\mathrm{A}-\mathrm{C})$ $-4.35 \times 10^{-3} \mathrm{BC}(\mathrm{B}-\mathrm{C})$. The equation shows that Cremophor RH40 surfactant has the most influence on the zeta potential value. Even though Cremophor RH40 is a nonionic surfactant, it can be charged due to the fabrication process's influence.

The three-dimensional (3D) surface plot shows the relationship between the experimental design's variance and response and helps understand these relationships quickly and easily. The $3 \mathrm{D}$ plot of the percent transmittance response, emulsification time, particle size, and zeta potential is presented in Figure 1.

The ANOVA results indicated that the percent transmittance response model is linear, the

Table 2. Analysis of variance and lack of fit tests of the model for the responses.

\begin{tabular}{|c|c|c|c|c|}
\hline Response & Model & p-value & Lack of fit (p-value) & F value \\
\hline Y1 & Linear & 0.001 & 0.131 & 11.880 \\
\hline Y2 & Special Cubic & 0.001 & 0.779 & 11.330 \\
\hline Y3 & Cubic & 0.269 & 0.550 & 1.690 \\
\hline Y4 & Cubic & 0.05 & 0.392 & 4.100 \\
\hline
\end{tabular}

Table 3. Summary of the regression analysis of the responses.

\begin{tabular}{|c|c|c|c|}
\hline Response & $\mathrm{R}^{2}$ & Adjusted- $\mathrm{R}^{2}$ & ${\text { Predicted } \mathrm{R}^{2}}^{2}$ \\
\hline $\mathrm{Y} 1$ & 0.646 & 0.592 & 0.467 \\
\hline $\mathrm{Y} 2$ & 0.883 & 0.805 & 0.659 \\
\hline $\mathrm{Y} 3$ & 0.717 & 0.293 & -13.034 \\
\hline $\mathrm{Y} 4$ & 0.860 & 0.650 & -12.125 \\
\hline
\end{tabular}


Design-Expert® Software Component Coding: Actual Overlay Plot

Percent transmittance Emulsification time (second) Droplet size $(\mathrm{nm})$

Zeta potential $(\mathrm{mV})$

- Design Points

$\mathrm{X} 1=\mathrm{A}:$ Cremophor RH40

$\mathrm{X} 2=\mathrm{B}: \mathrm{PEG} 400$

$\mathrm{X} 3=\mathrm{C}:$ Miglyol $812 \mathrm{~N}$

Figure 2. The plot overlay of optimum formula.

model of emulsification time is special cubic, and the models of particle size and zeta potential are cubic. All responses showed a p-value less than 0.05 except for particle size responses (Table 2), indicating that the model response is significant ( $p$ $<0.05$ ) and the model fits with variations of the observed replication (38). Moreover, the lack of fit test was another useful statistical parameter for checking a model's suitability. The lack of fit test was aimed to compare the residual error with the pure error from the replicated design points. A model with a non-significant lack of fit value is highly desirable in this experimental analysis (39). The lack of fit results from all responses paired in the model showed non-significant results $(p>0.05)$, indicating that the model was adequately fit. The
A: Cremophor RH40 (\%)

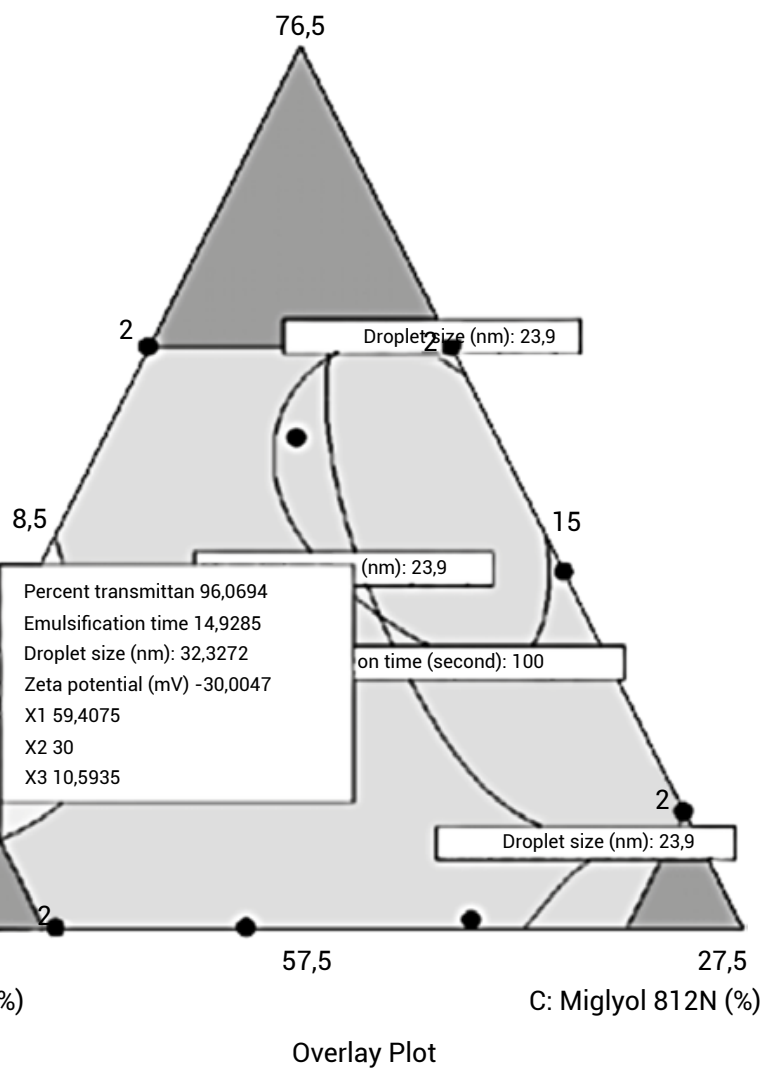

analysis of variance and lack of fit values indicate that the model fits the data in the observed replication variations.

The goodness of fit of the regression model can be seen from the $\mathrm{R}^{2}$ and adjusted $\mathrm{R}^{2}$ values. High $\mathrm{R}^{2}$ and adjusted $\mathrm{R}^{2}$ values indicate a good variability of the selected model (39). Table 3 shows the values of the multiple regression analysis of the model for all responses. The four responses had relatively high $\mathrm{R}^{2}$ dan adjusted $\mathrm{R}^{2}$ values, indicating a good correlation between the independent variables and the resulting responses (40). Afterward, all responses were used to determine the optimum SNEDDS formula due to having met the good model's response prediction requirements.

Table 4. Comparison of observed experimental and predicted values of isolated piperine-loaded SNEDDS under optimum conditions $(\mathrm{n}=3)$.

\begin{tabular}{|c|c|c|c|}
\hline Response & Observed value & Predicted value & p-value (one sample t-test) \\
\hline Percent transmittance & $96.35 \pm 0.33$ & 96.07 & 0.286 \\
\hline Emulsification time & $14.91 \pm 0.09$ & 14.93 & 0.815 \\
\hline Droplet size & $33.35 \pm 1.98$ & 32.22 & 0.468 \\
\hline Zeta potential & $-22.73 \pm 3.08$ & -30.01 & 0.055 \\
\hline
\end{tabular}


Table 5. Systems suitability parameters.

\begin{tabular}{|c|c|c|c|}
\hline Parameters & Data obtained & RSD $(\%)$ & Requirement \\
\hline Peak area & $75489.17 \pm 1239.22$ & $1.64 \%$ & RSD $<1 \%$ \\
\hline Retention time (min) & $7.70 \pm 0.02$ & $0.21 \%$ & $\mathrm{RSD}<1 \%$ \\
\hline Tailing factor & $1.39 \pm 0.03$ & & $\mathrm{~T} \leq 2$ \\
\hline Theoretical plate & $8611.50 \pm 48.13$ & & $\mathrm{~N}>2000$ \\
\hline Resolution & $4.35 \pm 0.07$ & & $\mathrm{Rs}>2$ \\
\hline Retention (Capacity) factor & $2.12 \pm 0.01$ & & $\mathrm{~K} \geq 2$ \\
\hline
\end{tabular}

$\mathrm{a}=$ mean of six repetition

The optimum formula determination of the software design expert is based on the approach of the desirability value generated by the model of all responses. The higher the desirability value, which is close to 1 , the better predicting the desired response $(41,42)$. The software analysis showed that the highest desirability value is 0.88 , containing a combination of Cremophor RH40 (59.41\%), PEG400 (30\%), and Miglyol $812 \mathrm{~N}(10.59 \%)$ (Figure 2). Afterward, the optimum formula from the predictive software results was triplicated and then evaluated to validate the response predicted by the software (Table 4).

\section{Drug content}

The content of isolated piperine was determined using High-Performance Liquid Chromatography (HPLC) with a validated method. The system suitability parameters of the val-

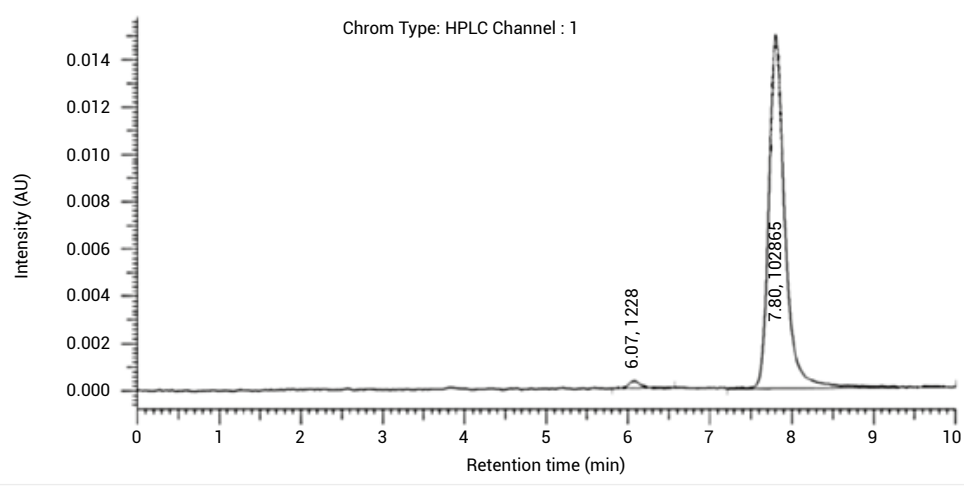

Figure 3. Chromatogram of piperine reference substance $(0.50 \mu \mathrm{g} / \mathrm{mL})$ at $340 \mathrm{~nm}$.

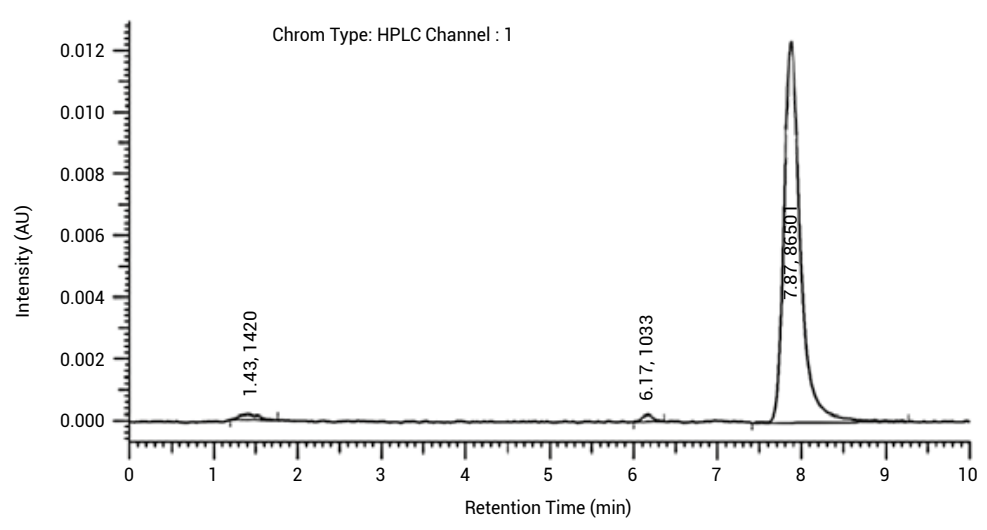

Figure 4. Chromatogram of isolated piperine $(0.50 \mu \mathrm{g} / \mathrm{mL})$ at $340 \mathrm{~nm}$.

idation method are presented in Table 5 . The chromatogram of the piperine reference substance and the isolated piperine at the wavelength of $340 \mathrm{~nm}$ are presented in Figure 3 and Figure 4. Following are the results of the validation of the analysis method for determining the content of isolated piperine in the SNEDDS optimum formula.

\section{Linearity}

Linear regression analysis was used to determine the slope, intercept, and

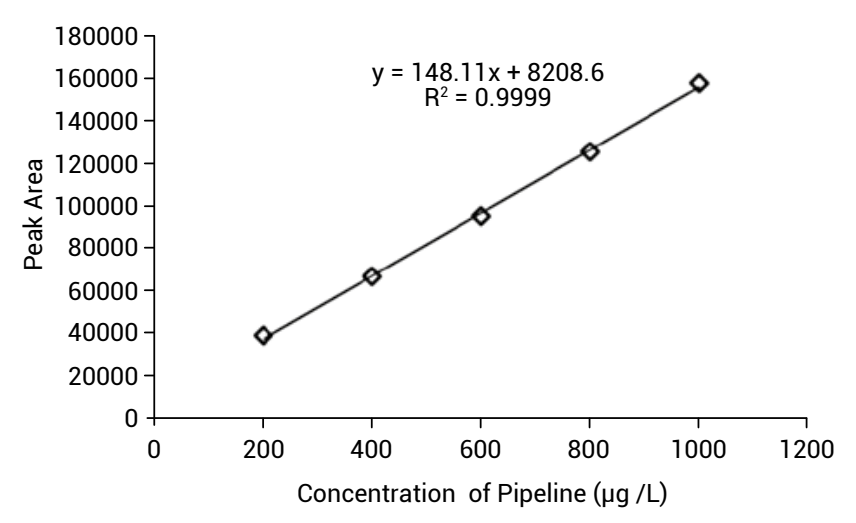

Figure 5. Calibration curve of a piperine reference substance at $340 \mathrm{~nm}$. 
Table 6. Method validation parameters for quantification of piperine.

\begin{tabular}{|c|c|}
\hline Parameters & Data obtained \\
\hline Linearity equation & $\mathrm{Y}=148.11 \mathrm{x}+8208.60$ \\
\hline Correlation coefficient $(\mathrm{r})$ & 0.9999 \\
\hline LOD $(\mu \mathrm{g} / \mathrm{L})$ & 9.23 \\
\hline LOQ $(\mu \mathrm{g} / \mathrm{L})$ & 30.77 \\
\hline Precision intra-day $(\% \mathrm{RSD})$ & 1.59 \\
\hline Precision inter-day $(\%$ RSD) & 3.75 \\
\hline Recovery $(\%)$ & $90.61-100.78$ \\
\hline
\end{tabular}

regression coefficient obtained by plotting the area versus the standard solution's concentration. The linear response results showed an excellent linear range with the $\mathrm{R}^{2}$ value of 0.9999 (Figure 5). According to Chan (43), the $\mathrm{R}^{2}$ value of the calibration curve should be greater than $\geq 0.997$, verifying that the linearity obtained in this study in response to external standards is adequate for the intended goal.

\section{Precision}

Assessment of the analytical method's precision was carried out with three different concentrations of isolated piperine that were injected at three different times on the same day and repeated on three different days to obtain intra-day and interday variations. The \% RSD results obtained intraday (1.59\%) and interday (3.75\%) indicated that the proposed analysis method is appropriate (Table 6). The percentage of RSD acceptance based on Horwitz and AOAC equations at the analyte level of less than $1 \mathrm{ppm}$ were 16 and 11 , respectively (44).

\section{Accuracy}

The analytical method's accuracy was assessed using an additional standard method by adding the piperine standard to the SNEDDS formulation of isolated piperine. A good recovery value is within the acceptable accuracy requirement, ranging $98-102 \%$ for active pharmaceutical substances and 95-105\% for active synthetic substances in pharmaceutical preparations (45). $\mathrm{The} \%$ recovery results obtained were $90.61-100.78 \%$ (Table 6). Accuracy testing is crucial for the development of herbal product methodologies. The recovery, which ranged between $80-100 \%$, produced a good accuracy value for herbal product preparations. It showed that the proposed method was accurate.

\section{Limits of detection (LOD) and quantification (LOQ)}

LOD and LOQ values were determined statistically using the calibration curve equation at the lowest concentration, which still produced a linear line. LOD and LOQ values were used to demonstrate a method's ability to detect and a substance's low concentration (46). The LOD and LOQ values of the piperine standard were 9.23 and $30.77 \mu \mathrm{g} / \mathrm{L}$, respectively (Table 6).

\section{Piperine isolate quantification}

The SNEDDS optimum formula contains $19.88 \pm 0.10 \mathrm{mg} / \mathrm{g}$ isolated piperine, which was determined using HPLC with a validated analytical method.

\section{CONCLUSION}

This study shows that SNEDDS containing isolated piperine has been successfully optimized using the D-optimal design. The measured values of the optimum formula consisting of isolated piperine $(1.94 \% \mathrm{w} / \mathrm{w})$, Cremophor RH40 (58.25\% w/w), PEG400 (29.42\% w/w), and Miglyol 812 N (10.39\% $\mathrm{w} / \mathrm{w})$ follow the predictive value generated by the software. It can be concluded that the D-optimal design is suitable for optimizing the SNEDDS formulation efficiently.

\section{Acknowledgment}

The authors would like to thank the Ministry of Research, Technology, and Higher Education of the Republic of Indonesia for providing financial support during this research via the Master Degree to Doctoral Program for Excellent Graduate Student (PMDSU) scheme year of 2018-2020. 


\section{Conflict of interest}

The authors declare no conflicts of interest.

\section{REFERENCES}

1. Zheng J.Y.: Formulation and Analytical Development for Low-Dose Oral Drug Products, pp. 23-48, John Wiley \& Sons, New York (2009).

2. Aungst B.J.: J. Pharm. Sci. 82, 979 (1993).

3. Sinha S., Ali M., Baboota S., Ahuja A., Kumar A., Ali J.: AAPS PharmSciTech 11, 518 (2010).

4. Kotta S., Khan A.W., Pramod K., Ansari S.H., Sharma R.K., Ali J.: Expert Opin. Drug Deliv. 9, 585 (2012).

5. Miyake K., Arima H., Hirayama F., Yamamoto M., Horikawa T., et al.: Pharm. Dev. Technol. 5, 399 (2000).

6. Khan A. W., Kotta S., Ansari S. H., Sharma R.K., Ali J.: Expert Opin. Drug Deliv. 9, 1305 (2012).

7. Wattanathorn J., Chonpathompikunlert P., Muchimapura S., Priprem A., Tankamnerdthai O.: Food Chem. Toxicol. 46, 3106 (2008).

8. Li S., Wang C., Wang M., Li W., Matsumoto K., Tang Y.: Life Sci. 80, 1373 (2007).

9. Mujumdar A.M., Dhuley J.N., Deshmukh V.K., Raman P.H., Naik S.: Jpn. J. Med. Sci. Biol. 43, 95 (1990).

10. Koul I.B., Kapil A.: Planta Med. 59, 413 (1993).

11. Ee G.C.L., Lim C.M., Rahmani M., Shaari K., Bong C.F.J.: Molecules 15, 2398 (2010).

12. Han Y., Chin Tan T.M., Lim L.-Y.: Toxicol. Appl. Pharmacol. 230, 283 (2008).

13. Srinivasan K.: Crit. Rev. Food Sci. Nutr. 47, 735 (2007).

14. Khajuria A., Thusu N., Zutshi U.: Phytomedicine 9, 224 (2002).

15. Wu Z., Xia X., Huang X.: J. Jinan Univ. 33, 473 (2012).

16. Kerns E.H., Di L.: Drug-like Properties: Concepts, Structure Design and Methods. Elsevier, Academic Press (2008).

17. Singh B., Bandopadhyay S., Kapil R., Singh R., Katare O.: Crit. Rev. Ther. Drug Carrier Syst. 26, 427 (2009).

18. Song W.H., Yeom D.W., Lee D.H., Lee K.M., Yoo H.J., et al.: Arch. Pharm. Res. 37, 626 (2014).

19. Mahmoud E.A., Bendas E.R., Mohamed M.I.: AAPS PharmSciTech 10, 183 (2009).
20. Nielsen F.S., Petersen K.B., Müllertz A.: Eur. J. Pharm. Biopharm. 69, 553 (2008).

21. Gursoy R.N., Benita S.: Biomed. Pharmacother. 58, 173 (2004).

22. Porter C.J.H., Pouton C.W., Cuine J.F., Charman W.N.: Adv. Drug Deliv. Rev. 60, 673 (2008).

23. Lee D.W., Marasini N., Poudel B.K., Kim J.H., Cho H.J., et al.: J. Microencapsul. 31, 31 (2014).

24. Mathieu R., Baghdadi I., Briat O., Gyan P., Vinassa J.-M.: Energy 141, 2108 (2017).

25. Hooda A., Nanda A., Jain M., Kumar V., Rathee P.: Int. J. Biol. Macromol. 51, 691 (2012).

26. Badran M.M., Taha E.I., Tayel M.M., AlSuwayeh S.A.: J. Mol. Liq. 190, 16 (2014).

27. Krstić M., Medarević Đ., Đuriš J., Ibrić S.: Lipid Nanocarriers for Drug Targeting (ed. Grumezescu A.M. Ed., pp. 473-508, William Andrew Publishing, 2018.

28. Mohd A.B., Sanka K., Bandi S., Diwan P.V., Shastri N.: Drug Deliv. 22, 499 (2015).

29. Cerpnjak K., Zvonar A., Gašperlin M., Vrečer F.: Acta Pharm. 63, 427 (2013).

30. Liu H., Luo R., Chen X., Liu J., Bi Y., et al.: J. Chromatogr. B Analyt. Technol. Biomed. Life Sci. 928, 78 (2013).

31. Khan A.W., Kotta S., Ansari S.H., Sharma R.K., Ali J.: Drug Deliv. 22, 552 (2015).

32. Salem H.F., Kharshoum R.M., Sayed O.M., Abdel Hakim L.F.: J. Liposome Res. 29, 195 (2019).

33. Cornell J.A.: Experiments with Mixtures: Designs, Models, and the Analysis of Mixture Data, Third Edition pp. 223-285, John Wiley \& Sons, Inc., New Jersey 2002.

34. Parmar N., Singla N., Amin S., Kohli K.: Colloids Surf. B Biointerfaces 86, 327 (2011).

35. Rang M-J., Miller A.M.: J. Colloid Interface Sci. 209, 179 (1999).

36. Bandyopadhyay S., Katare O.P., Singh B.: Colloids Surf. B Biointerfaces 100, 50 (2012).

37. Cherniakov I., Domb A.J., Hoffman A.: Expert Opin. Drug Deliv. 12, 1121 (2015).

38. Fauzi S.H.M., Rashid N.A., Omar Z.: Food Chem. 137, 8 (2013).

39. Myers R.H., Montgomery D.C., AndersonCook C.M.: Response Surface Methodology. Process and Product Optimization Using Designed Experiments. John Wiley \& Sons, Inc., New Jersey 2009. 
40. Khanolkar A., Thorat V., Raut P., Samanta G.: AAPS PharmSciTech 18, 2754 (2017).

41. Malakar J., Sen S.O., Nayak A.K., Sen K.K.: Saudi Pharm. J. 20, 355 (2012).

42. Marasini N., Yan Y.D., Poudel B.K., Choi H-G., Yong C.S., Kim J.O.: J. Pharm. Sci. 101, 4584 (2012).

43. Chan C.C., Lam H., Lee Y.C., Zhang X-M.: Analytical Method Validationand Instrument
Performanceverification. John Wiley \& Sons, Inc., New Jersey 2004.

44. Gustavo González A., Ángeles Herrador M.: TrAC Trends Analyt. Chem. 26, 227 (2007.

45. Ferenczi-Fodor K., Végh Z., Nagy-Turák A., Renger B., Zeller M.: J. AOAC Int. 84, 1265 (2001).

46. Coelho E.M., da Silva Padilha C.V., Miskinis G.A., de Sá A.G.B., Pereira G.E., et al.: J. Food Compos. Anal. 66, 160 (2018).

(C) 2021 by Polish Pharmaceutical Society. This is an open-access article under the CC BY NC license (http://creativecommons.org/licenses/BY/4.0/). 